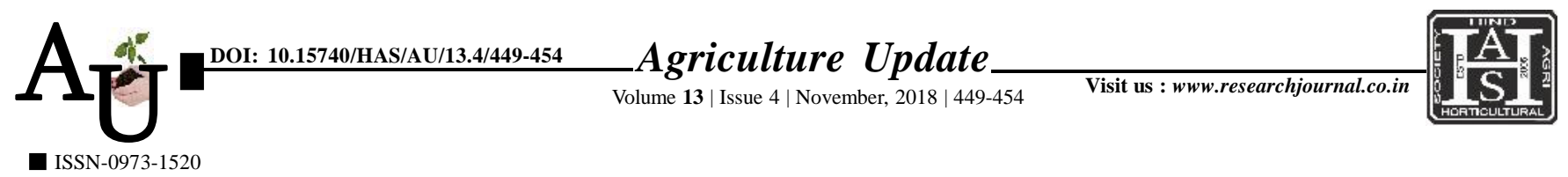

\title{
Research Article: A study on repayment behaviour of agricultural loan borrowers through commercial banks
}

Grashant Maratha

Article Chronicle :

Received :

02.09.2018;

Revised :

01.10.2018;

Accepted :

17.10.2018

\section{Key Words :}

Repayment

behaviour,

Agricultural loan,

Borrowers,

Commercial banks
SUMMARY : The study was conducted in purposively selected Bundi district of Rajasthan. Total of 500 agricultural loan borrowers were formed the sample for the study. The primary data were collected through personal interview method with the help of pre-tested interview schedule, which was prepared on the basis of objectives of investigation and variables. The statistical tests and procedures were used for analyzing the data with the help of statistical tools like- mean, S.D., percentage and Karl Pearson's co-efficient of correlation, multiple correlation and regression analysis. We found that 67.60 per cent borrowers paid their dues on time and to be called as "Regular" or standard borrowers It was observed that correlation co-efficients in respect of sources of information, Cosmo-politeness, scientific orientation and risk preference were found positive and highly significant with repayment behaviour of farmers. Co-efficient of determination value of 0.5514 with highly significant ' $F$ ' value revealed the significance of regression equation in the prediction of repayment behaviour of farmers. Out of sixteen traits viz., caste, annual income, cosmopoliteness, scientific orientation and risk preference were found positive and highly significant relationship with repayment behaviour of farmers. Crop raze due to natural hazards as major constraints for effective repayment behaviour by borrowers and curb less financing, effective crop insurance and procedure of loaning should be more sophisticated were the main suggestion offered by borrowers for effective repayment behaviour of the borrowers.

How to cite this article : Maratha, Prashant (2018). A study on repayment behaviour of agricultural loan borrowers through commercial banks. Agric. Update, 13(4): 449-454; DOI : 10.15740/HAS/AU/13.4/449-454. Copyright@2018: Hind Agri-Horticultural Society.
Author for correspondence :

Prashant Maratha

University Kota, Kota (Rajasthan) India

Email: Prashantmaratha @ gamil.com 